\title{
CARACTERIZAÇÃO DA REATIVIDADE DE AGREGADOS DOS CAMPOS GERAIS DO ESTADO DO PARANÁ
}

\author{
FARIAS, MARCELO MIRANDA \\ Engenheiro Civil \\ Universidade Estadual de Ponta Grossa \\ Paraná, Brasil \\ mirandafariasmarcelo@gmail.com
}

\author{
VALENGA, MATHEUS VILLIAN \\ Estudante de Engenharia Civil \\ Universidade Estadual de Ponta Grossa \\ Paraná, Brasil \\ matheusvvalenga666@gmail.com
}

\author{
PEREIRA, ELIAS \\ Professor Mestre \\ Universidade Estadual de Ponta Grossa \\ Paraná, Brasil \\ elias_pereira@outlook.com \\ PEREIRA, EDUARDO \\ Professor Doutor \\ Universidade Estadual de Ponta Grossa \\ Paraná, Brasil \\ eduardopereira@uepg.br
}

\section{RESUMO}

O concreto, um dos materiais mais utilizados na construção civil, pode estar sujeito a diversos tipos de manifestações patológicas que podem causar sua degradação. Entre estas manifestações pode-se citar o ataque interno por sulfatos (ISA) e a reação álcali-agregado (RAA), que vêm afetando diversas obras como fundações e barragens. Tanto um ataque quanto outro, podem estar relacionados com o tipo de agregado utilizado no concreto e, por esse motivo, é de extrema importância o conhecimento de como os constituintes do concreto se comportam em contato com esses minerais. No presente trabalho, realizou-se o estudo de agregados de seis pedreiras da região dos Campos Gerais, no estado do Paraná, caracterizando-os quanto às suas composições e suas reatividades em contato com os componentes do concreto, sendo os resultados comparados com um agregado referência, o qual não apresentava RAA nem ISA. Avaliou-se a expansão de barras de argamassa a partir de ensaios para verificação de variação dimensional linear, possibilitando observar alterações dimensionais das mesmas devido aos ataques. Ensaios complementares de difratometria, fluorescência de raios X e microscopias também foram realizados, possibilitando a verificação dos produtos formados no interior das barras de argamassa. Dentre os agregados estudados, $70 \%$ deles se mostraram reativos em contato com o cimento, apresentando formação de compostos expansíveis em seu interior. Constatou-se também que teores de cálcio maiores que $7 \%$ e de sódio maiores que 5\% na composição química do agregado, influenciaram numa maior formação do gel higroscópico advindo da RAA.

Palavras-chave: reação álcali-agregado, ataque interno por sulfatos, concreto, durabilidade.

\section{ABSTRACT}

The concrete, one of the most used materials in constructions, is subjected to many types of pathological manifestations that leads in its degradation. Among these manifestations, the internal sulfate attack (ISA) and the alkali-aggregate reaction (AAR) are examples of attacks that have been affecting structures of foundations and dams. Both attacks can be related with the type of aggregate used in the concrete and, for this reason, it is extremely important the knowledge of how the concrete compounds behaves when in contact with these minerals. In this research, aggregates from six different quarries of the Campos Gerais region, located in the Paraná State, Brazil, were studied. Their mineralogical compositions and their reactivities with concrete compounds were characterized, being compared with a referential aggregate, which one has not AAR or ISA reactions. The expansions of prismatic mortar bars were evaluated, allowing the observation of the linear dimension variation caused by the attacks. Complementary tests as X-Ray diffractometry, $\mathrm{X}$-Ray fluorescence and microscopy (FEG) were made, making possible the verification of the formed products inside the mortar bars. Among the studied aggregates, $70 \%$ of them were classified as reactive with cement, since they presented the formation of expansive products inside the prismatic bars. It was also verified that calcium contents above $7 \%$ and sodium contents above $5 \%$ in the chemical composition of the aggregate, can influence in a greater formation of hygroscopic gel, an alkali-aggregate reaction product.

Keywords: alkali-aggregate reaction, internal sulfate attack, concrete, durability. 


\section{INTRODUÇÃO}

Inúmeras características fazem com que o concreto tenha o título de material de construção mais usado na Engenharia, ficando atrás apenas do uso água. Isso se deve ao fato de que o concreto permite a construção de elementos estruturais de várias formas e tamanhos, além de ter um custo baixo e maior disponibilidade para seu uso no canteiro de obra, comparado a outros materiais. Aparentemente tão durável, observou-se há algumas décadas que o concreto pode apresentar interações ambientais que, como consequência, dão origem a mudanças em suas propriedades e na sua microestrutura. A partir desse ponto, passou-se a ser questionada a durabilidade do concreto que, mesmo sendo projetado e executado de forma correta, pode apresentar sinais de deterioração [1].

As deteriorações neste material são devidas a fatores extrínsecos e intrínsecos, sendo essas deteriorações classificadas em dois tipos, as físicas e químicas [2]. Dentre as deteriorações químicas pode-se citar a hidrólise dos componentes da pasta de cimento, as trocas iônicas entre pasta e fluídos agressivos, reações álcali-agregado (RAA), ataques internos por sulfatos (Internal Sulfate Attack - ISA), corrosão da armadura do concreto, entre outros, sendo que essas reações são deletérias e com consequências negativas para a microestrutura e propriedades do concreto [1]-[2]-[3].

Tanto a reação álcali-agregado (RAA), quanto o ataque interno por sulfatos (ISA), consistem da presença de componentes suscetíveis a reações físico-químicas com a pasta de aglomerante hidratada dentro da estrutura, que podem desencadear manifestações patológicas. O diagnóstico dessas manifestações é difícil nas primeiras idades, já que podem levar anos para que sejam observadas macroscopicamente [2]-[4].

A reação álcali-agregado (RAA) é a formação de um gel higroscópico pela reação entre íons hidroxila e hidróxidos alcalinos (provenientes da hidratação do cimento) com alguns constituintes do agregado utilizado no concreto. Esse gel é uma substância viscosa que atrai moléculas de água, fazendo com ele expanda e, consequentemente, gere tensões no interior da estrutura. As principais manifestações patológicas observadas são a exsudação de gel na superfície do concreto, fissuras em "mapa", formação de manchas, entre outros [5].

Alguns fatores podem potencializar a reação álcali-agregado, como maiores teores de álcalis no cimento, o agregado utilizado no concreto, que deve conter minerais reativos, como a sílica amorfa [6]-[7], e principalmente a umidade e temperatura do meio [8]-[9].

Já o ataque interno por sulfatos (ISA) é a formação de compostos expansivos dentro dos poros do concreto, originados devido a reação entre sulfetos, oxigênio e umidade com os compostos hidratados do cimento. Esses compostos expansivos são cristais de etringita, gipsita e íons férricos. Esse ataque causa manifestações patológicas como fissuras e redução da resistência mecânica que, em casos mais avançados, pode levar a estrutura ao colapso [2]-[10]-[11].

Os sulfatos de origem interna são provenientes da água usada na hidratação, de agregados que possam estar contaminados ou do próprio aglomerante usado na mistura [12]. Quanto aos agregados, princípio deste estudo, podem ser de regiões diversas, e com características distintas. Em algumas regiões é possível encontrar a pirita (dissulfeto de ferro) associada à rocha, já que este é o sulfeto de ferro mais encontrado na natureza. Esses sulfetos têm grande capacidade de oxidar quando em ambientes com oxigênio e umidade, originando uma cadeia de reações que darão origem ao ataque interno por sulfatos [13].

\section{METODOLOGIA}

Para que fossem atendidos os objetivos desta pesquisa, observou-se a interação entre agregados de diferentes pedreiras da região dos Campos Gerais em contato com a pasta de cimento, comparando-os com um agregado referência que não apresentava nem reação álcali-agregado nem ataque interno por sulfatos. Os agregados coletados foram submetidos a ensaios de caracterização físicas e químicas, e com eles foram confeccionadas barras prismáticas de argamassa, que foram submetidas a ensaios de expansão dimensional linear, microscopia eletrônica de varredura, difratometria e fluorescência de raios-X, além do uso de microscópio ótico para observação da exsudação do gel higroscópico para o exterior das barras de argamassa.

Foram utilizados agregados miúdos de 6 (seis) jazidas denominadas de agregados das Pedreiras "A", "B", "C", "D", "E" e "F". Uma das pedreiras se localizava próximo ao município de Balsa Nova, outra no município de Castro e quatro dessas pedreiras se localizavam no município de Carambeí, sendo esses agregados classificados como industriais. 
Também se utilizou areia quartzosa proveniente do leito do rio Tibagi, localizado nos Campos Gerais, como material referência, sendo esse um agregado natural.

Os agregados foram peneirados e suas frações separadas para obtenção do material retido nas peneiras \#8, \#16, \#30, \#50 e \#100, definidas na norma americana [14]. Este procedimento foi necessário para a confecção das barras de argamassa, atendendo as especificações de granulometria exigidas na norma.

Para a caracterização química quantitativa e qualitativa dos agregados, utilizou-se do espectrômetro de fluorescência de raio X (FRX) por meio de energia dispersiva (EDX). Para a verificação de fases cristalinas constituintes das amostras, realizaram-se ensaios de difratometria de raios X (DRX). Os ensaios de FRX foram realizados em espectrômetro EDX 700 da marca SHIMADZU utilizando-se pastilhas de pós prensadas, enquanto os ensaios de DRX foram realizados em um difratômetro Rigaku Ultima IV.

Para os ensaios de avaliação de reatividade álcali-agregado em argamassa, foram moldadas barras de argamassa de acordo com as especificações da ASTM [14], tendo traço 1:2,25:0,47. Moldaram-se 4 (quatro) prismas com o uso de cada agregado, adotando-se duas camadas com 20 golpes, para que houvesse o adensamento adequado da argamassa no molde.

As barras de argamassa foram submetidas a ensaios para verificação da variação dimensional linear de acordo com a ASTM [14], possibilitando observar alterações dimensionais das mesmas devido aos ataques com o uso de um relógio comparador previamente calibrado, como demonstrado na Figura 1. O modo de cura utilizado foi acelerada, no qual as barras de argamassa foram imersas em solução de hidróxido de sódio à $80^{\circ}\left( \pm 1^{\circ}\right) \mathrm{C}$ por um período de 60 dias para que fosse possível se observar a interação entre a matriz cimentícea e os agregados. Esse tipo de cura foi escolhida pelo curto tempo disponível para obtenção dos resultados, na qual a alta temperatura e a maior presença do álcalis sódio na solução promovem uma intensificação de reações no interior das barras de argamassa.
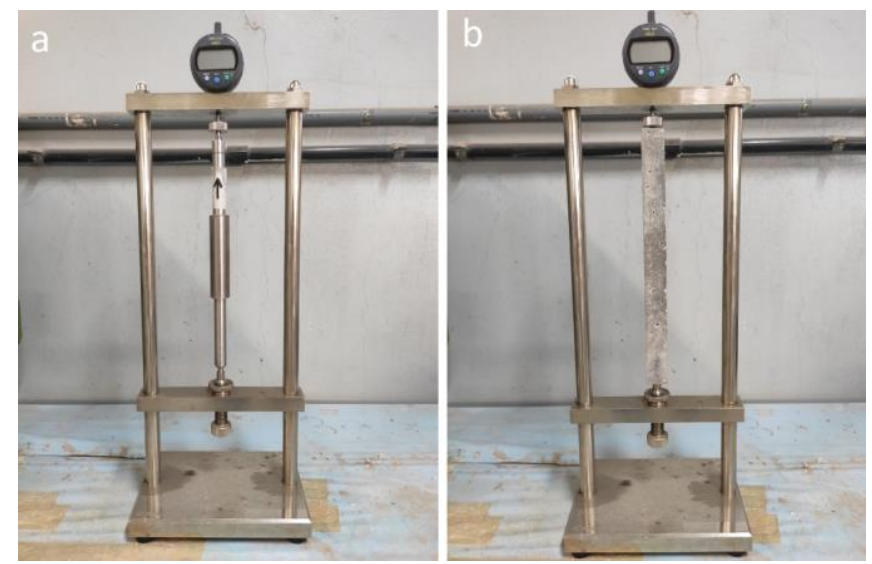

Figura 1: Relógio comparador utilizado para aferir expansões.

As barras de argamassa, após os 60 dias de cura acelerada em hidróxido de sódio, foram avaliadas por meio de microscopia eletrônica de varredura (FEG) para que fosse possível se observar a formação de gel ou cristais neoformados no interior da estrutura devido ao RAA e ISA, respectivamente. Realizaram-se ensaios de espectroscopia de raio $\mathrm{X}$ (EDS) para se obter uma análise qualitativa de produtos presentes no meio. As amostras também foram analisadas em microscópio óptico para se observar a presença de gel na parte periférica das amostras, assim como por meio de ensaios complementares de FRX e DRX para se obterem informaçöes sobre a formação de novos produtos e cristais durante o processo de cura.

\section{RESULTADOS}

Para se obterem informações sobre as características químicas dos agregados, realizaram-se ensaios de DRX e FRX. A Tabela 1 mostra os resultados de óxidos encontrados nos agregados de cada pedreira por meio de FRX. Importante ressaltar as maiores porcentagens de óxido de sódio $\left(\mathrm{Na}_{2} \mathrm{O}\right)$ para os agregados das pedreiras " $\mathrm{A}$ ", " $\mathrm{B}$ " e " $\mathrm{C}$ ", e de 
maiores valores de óxido de cálcio $(\mathrm{CaO})$ para os agregados " $\mathrm{D}$ " e " $\mathrm{F}$ ", ambos álcalis presentes em agregados, que poderão influenciar na formação de gel higroscópico proveniente de reações álcali-agregado.

Tabela 1: Caracterização química elementar dos agregados por fluorescências de raios X (\%).

\begin{tabular}{ccccccccccccc}
\hline & $\mathbf{C}$ & $\mathbf{N a}$ & $\mathbf{M g}$ & $\mathbf{A l}$ & $\mathbf{S i}$ & $\mathbf{S}$ & $\mathbf{K}$ & $\mathbf{C a}$ & $\mathbf{M n}$ & $\mathbf{F e}$ & $\mathbf{T i}$ & $\mathbf{Z r}$ \\
\hline REF & - & - & - & - & - & - & - & - & - & - & - & - \\
\hline A & 2,70 & 5,64 & 0,10 & 12,60 & 60,30 & 0,05 & 10,00 & 2,58 & 0,10 & 5,40 & - & 0,19 \\
\hline $\mathbf{B}$ & 2,54 & 5,36 & 0,12 & 12,40 & 59,50 & 0,11 & 9,31 & 2,09 & 0,12 & 7,37 & - & 0,25 \\
\hline C & 2,48 & 5,24 & 0,08 & 12,70 & 59,80 & - & 10,10 & 2,37 & - & 6,51 & - & 0,16 \\
\hline $\mathbf{D}$ & 2,08 & 3,16 & 3,43 & 12,80 & 47,30 & 0,06 & 7,61 & 7,29 & 0,24 & 14,30 & 1,01 & 0,07 \\
\hline E & 2,47 & 2,21 & 0,22 & 12,20 & 59,60 & 0,03 & 17,20 & 2,19 & - & 3,53 & - & 0,08 \\
\hline F & 2,41 & 2,91 & 3,71 & 12,00 & 36,00 & 0,21 & 1,80 & 13,00 & 0,29 & 23,90 & 3,22 & 0,06 \\
\hline
\end{tabular}

A maior presença de ferro, dependendo da forma cristalina que este estiver presente no interior do agregado, também pode influenciar na formação de cristais de etringita e gipsita devido ao ISA [15], o qual é visto em maiores proporções nos agregados "D" e "F".

Já para os ensaios de DRX dos agregados, de maneira geral, todos os agregados apresentaram quartzo em sua composição, mineral composto basicamente de sílica $\left(\mathrm{SiO}_{2}\right)$. O agregado Referência apresentou basicamente esse mineral cristalino em sua composição, como ilustrado na Figura 2 (a). Nos espectros de DRX dos demais agregados, observou-se a presença de plagioclásios $\left((\mathrm{Na}, \mathrm{Ca}) \mathrm{Al}(\mathrm{Si}, \mathrm{Al}) \mathrm{Si}_{2} \mathrm{O}_{8}\right)$, filossilicatos e de feldspatos alcalinos $((\mathrm{K}, \mathrm{Na})(\mathrm{Si}$, $\mathrm{Al}_{4} \mathrm{O}_{8}$ ), os quais fazem parte da classe dos silicatos, sendo esses os minerais mais comuns encontrados em rochas. Verificou-se também a presença de calcopirita na rocha da pedreira "F", mineral comum em rochas que estão sujeitas ao ataque interno por sulfatos, como demonstrado na Figura 2 (b).
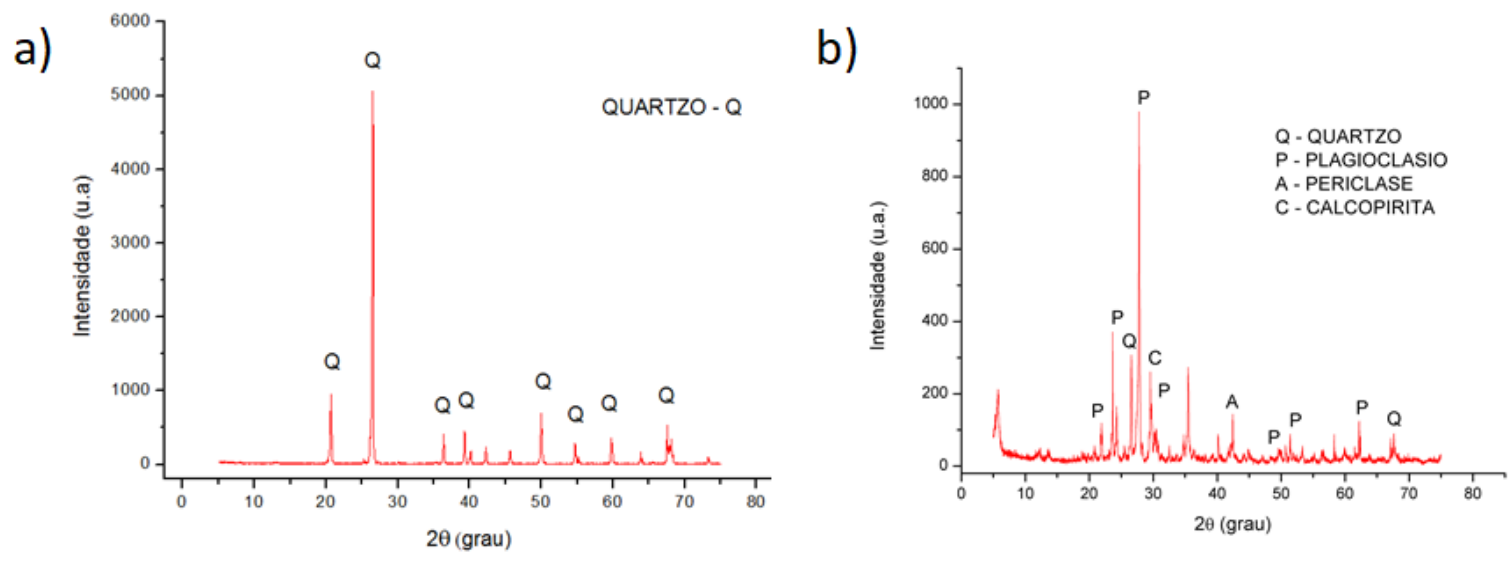

Figura 2: Composição mineralógica obtida por DRX do agregado Referência.

A partir do monitoramento de expansões das barras de argamassa em cura acelerada por 60 dias, pôde-se verificar, como ilustrado na Figura 3, a reatividade dos agregados com a pasta de cimento de acordo com o exposto pela ASTM [14]. Segundo a norma americana, se a expansão for inferior a 0,10\% aos 16 dias, em maior parte dos casos os agregados são inócuos. Se a expansão estiver entre 0,10\% e 0,20\% aos 16 dias, há possibilidade de o agregado possuir tanto comportamento inócuo como deletério e se a expansão se situar com valores maiores que 0,20\% aos 16 dias, o agregado possui expansão potencialmente deletéria devido à RAA. 


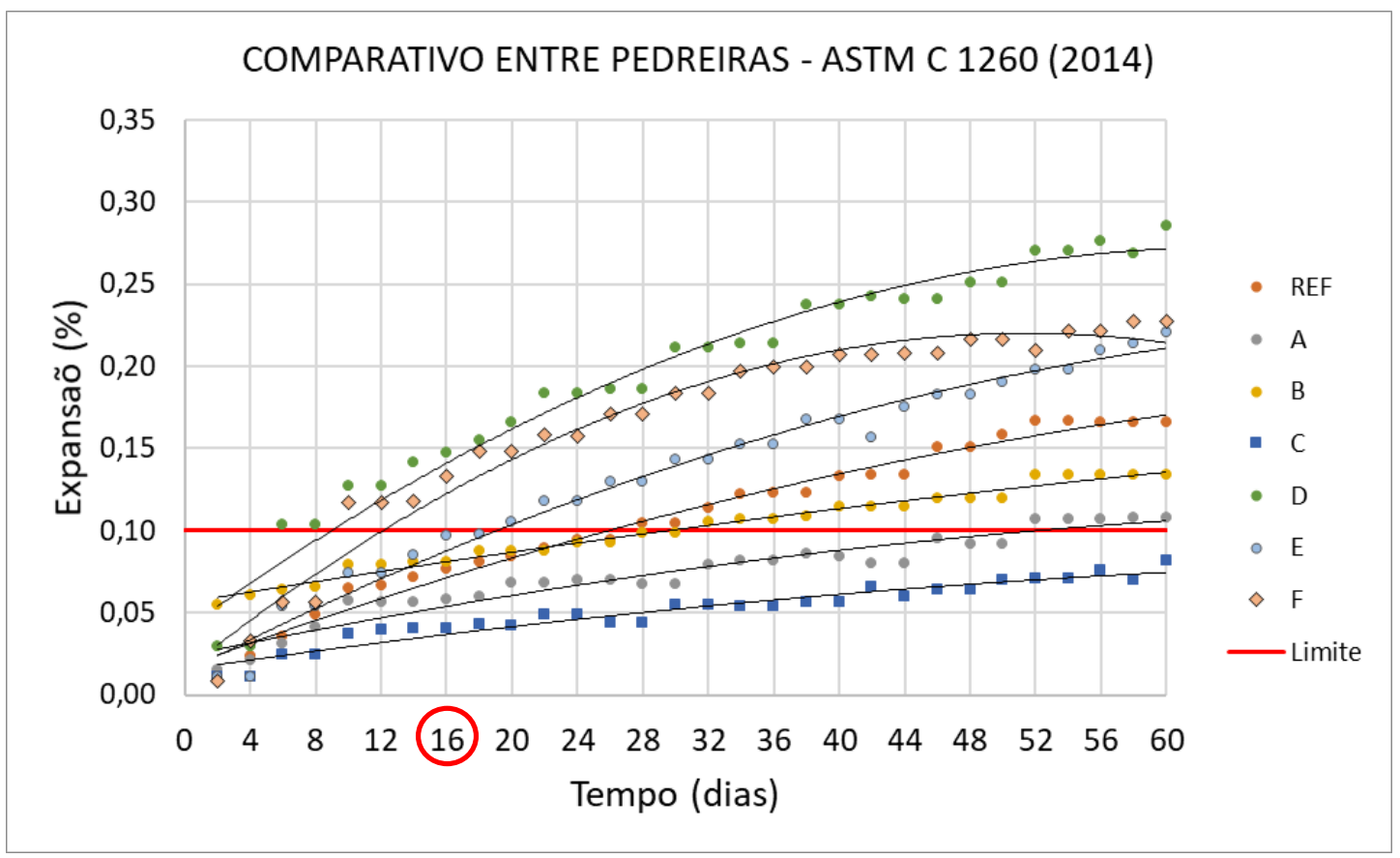

Figura 3: comparação de expansões entre as barras de argamassa com agregados das diferentes Pedreiras, de acordo com o limite da ASTM C 1260 (2014).

Como ilustrado pela Figura 3, para o agregado Referência, que consiste basicamente de areia quartzosa proveniente do leito do rio Tibagi, obteve-se uma expansão de $0,07 \%$ aos 16 dias de cura acelerada. Isso demonstra que esse agregado, em contato com a pasta de cimento, apresenta comportamento inócuo para a reação álcali-agregado, não sendo deletério, de acordo com a ASTM [14], ou seja, não são suscetíveis à formação do gel expansível. Os agregados "A", "B" e "C", apresentaram respectivamente expansões de $0,06 \%, 0,08 \%$ e $0,04 \%$ aos 16 dias de cura, ou seja, também foram classificados como inócuos de acordo com a norma americana.

Em contrapartida, como observado na Figura 3, os agregados "D", "E" e "F" apresentaram respectivamente expansões de $0,15 \%, 0,10 \%$ e $0,13 \%$ aos 16 dias, sendo assim classificados segundo a ASTM [14] como agregados inócuos ou reativos, recomendando-se a realização de ensaios complementares para a efetiva comprovação da reatividade dos mesmos.

Tanto para o agregado Referência quanto para o agregado da pedreira "E", não foi possível visualizar a formação de cristais devido ao ataque interno por sulfatos após 60 dias de cura acelerada, nem como formação do gel no interior da microestrutura ou na superfície das barras de argamassa, como demonstrado na Figura 4. Apenas esses agregados em contato com a argamassa, dentre todos os estudados, não apresentaram formação de compostos expansíveis no interior da estrutura.
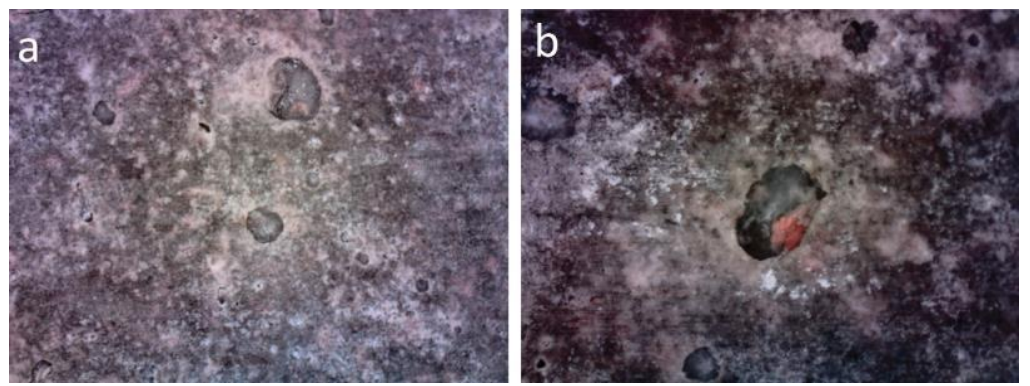

Figura 4: Superfície da barra de argamassa com agregado Referência (a) e agregado "E" (b) por meio de microscópio ótico.

Cristais provenientes do ataque interno por sulfatos não estavam presentes nas microscopias realizadas na matriz cimentícia, já que ambos os agregados não possuem sulfetos em sua composição mineralógica. O gel higroscópico também não foi observado em nenhuma das barras com a presença do agregado Referência e "E". Vale ressaltar que, 
como observado na Tabela 1, esses dois agregados citados apresentaram os menores teores de álcalis cálcio e sódio na sua composição mineralógica, influenciando assim na menor formação de gel, já que os álcalis são componentes essenciais para a formação do gel.

Para as argamassas com agregados das pedreiras "A" e "B", houve a formação de gel devido à reação álcali-agregado, provavelmente ligado à maior quantidade de álcalis de sódio (maior que 5\%) na composição desses agregados. A Figura 5 (a) mostra a presença de gel na microscopia da amostra de argamassa "A", enquanto a Figura 5 (b) é uma imagem da superfície da barra de argamassa, na qual também é possível observar a presença de gel.
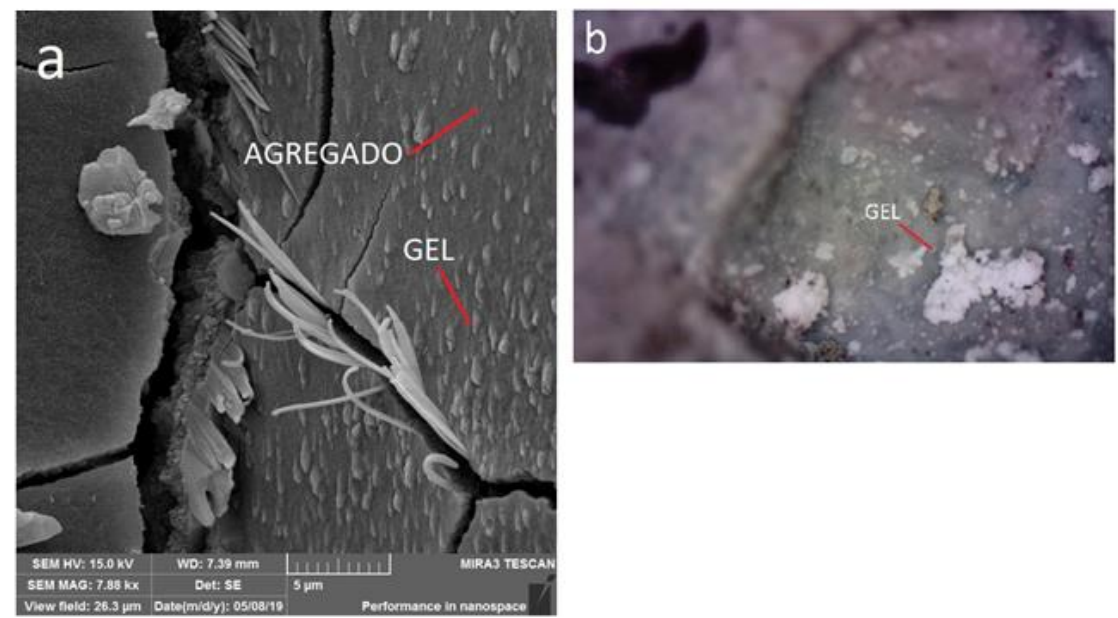

Figura 5: a) Gel higroscópico formado no agregado "A" devido ao RAA. b) Gel exsudado nos poros da superfície da barra com agregado da pedreira "A".

Para o agregado "A", por meio de DRX, observou-se a presença de quartzo com halos amorfos. Também se notou a presença de fases de calcita, presente devido ao fíler do cimento, e fases de portlandita, comum devido à formação de hidróxido de cálcio durante a hidratação do cimento. Foi observada também a presença de C-S-H e albita, que é um feldspato plagioclásio presente na rocha, como demostrado na Figura 6.

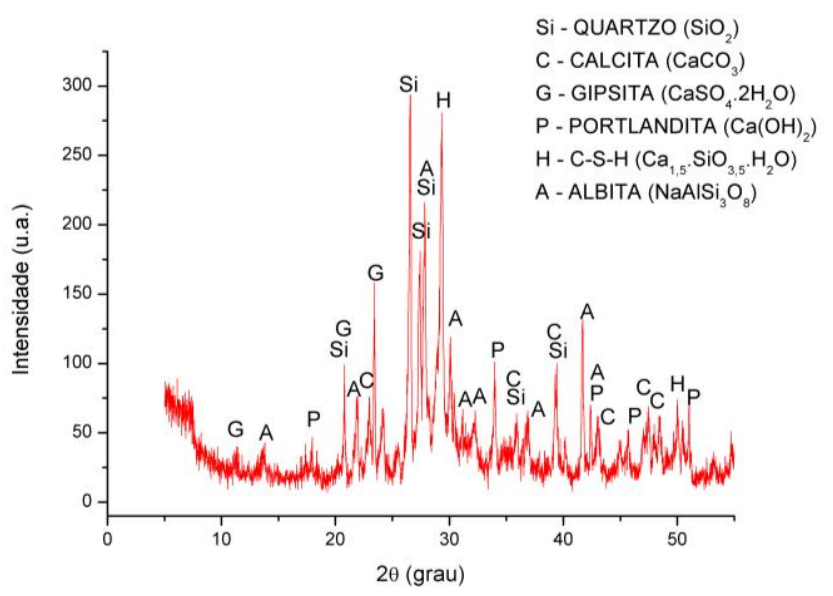

Figura 6: Difratograma de raio $\mathrm{X}$ da argamassa com agregado da pedreira "A".

Além das fases citadas, pôde-se observar a presença de gipsita. Não se pode afirmar que a gipsita seja originada devido ao ataque interno por sulfatos na argamassa, já que os cristais de gipsita não foram observados nas microscopias e o agregado "A" não apresentava sulfetos em sua composição mineralógica, existindo ainda a hipótese do DRX do agregado "A" não ter identificado fases de sulfetos durante a realização do ensaio.

A Figura 7 (a e b) mostra as fases reativas do agregado "B" solubilizando-se devido à solução alcalina da argamassa, sendo possível também visualizar a formação de gel na forma cristalina. Na Figura 7 (c) pode-se observar a exsudação do gel nos poros da superfície do agregado, por meio de microscópio óptico. Para as argamassas com agregados da pedreira "B", a partir do uso de DRX, foram encontradas fases observadas também nos agregados anteriores, 
apresentando quartzo, C-S-H, albita, portlandita e brownmilerite, que se forma devido as fases $\mathrm{C}_{4} \mathrm{AF}$ que não se hidrataram no cimento.
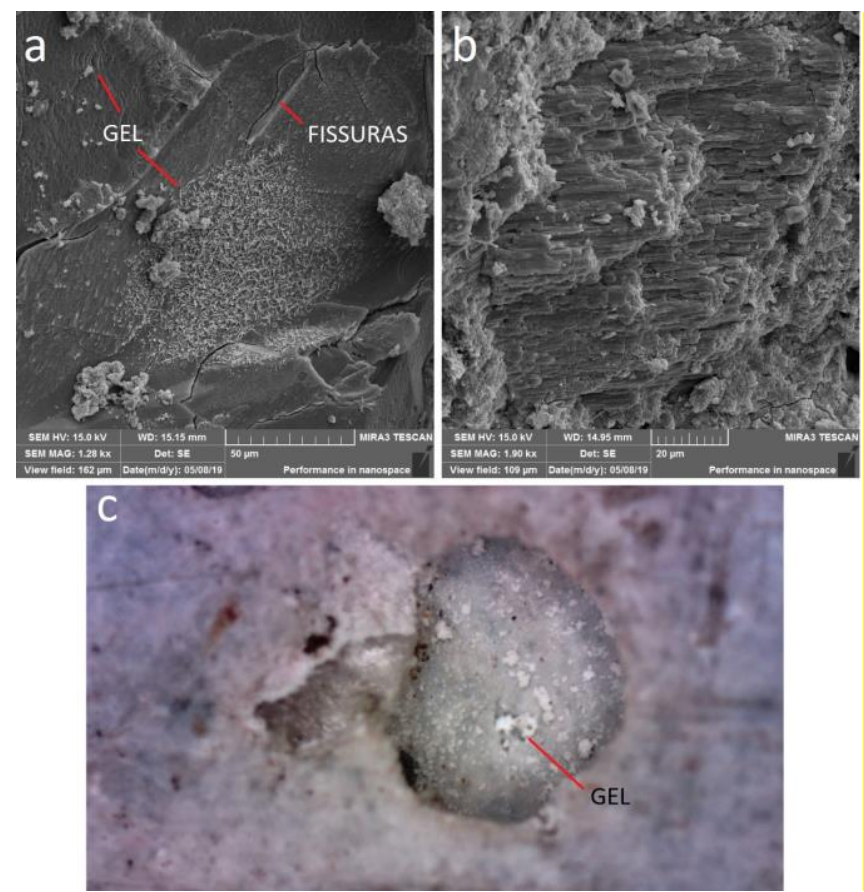

Figura 7: a) Fases reativas solubilizando-se na solução alcalina no agregado "B" devido ao RAA, formando fissuras no poro. c) Presença de gel no exterior das barras de argamassa.

Já nos agregados "C", "D" e "F" foram observadas tanto a formação de gel como de cristais. Observa-se na Figura 8 (a) a presença de gel na matriz da argamassa com o agregado da pedreira " $\mathrm{C}$ ", assim como a presença de fissuras formadas devido à expansão do mesmo. É possível notar na Figura 8 (c) a exsudação de gel para o exterior da barra com o agregado "C", devido à reação álcali-agregado.

Visto que as barras de argamassa do agregado "C" possuíram uma expansão de $0,04 \%$ aos 16 dias, que esse não apresenta enxofre ou sulfetos na sua composição mineralógica e que os cristais encontrados na microscopia se encontravam distribuídos de forma esparsa na matriz cimentícia (Figura 8 (b)), a etringita encontrada provavelmente se originou pelo processo natural de hidratação do cimento. 


\section{CBPAT 2020 \\ CONGRESSO BRASILEIRO DE PATOLOGIA DAS CONSTRUÇÕES \\ DE 15 A 17 DE ABRIL | FORTALEZA - CE}
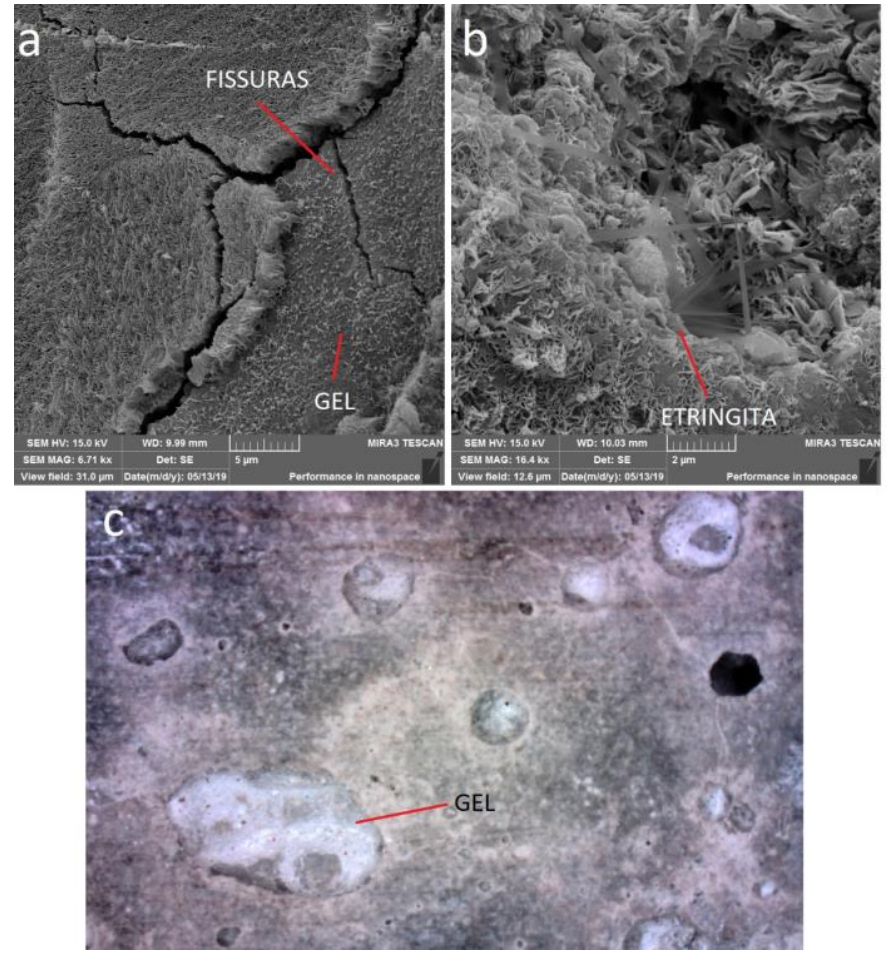

Figura 8: a) Presença generalizada de gel na argamassa com presença do agregado $C$ e formação de fissuras. b) Presença isolada de cristais de etringita. c) Exsudação de gel nos poros externos das barras de argamassa com agregado da pedreira "C".

Em contrapartida, os agregados "D" e " $F$ " apresentaram enxofre em sua composição mineralógica, assim como maior quantidade de ferro e de cristais na matriz cimentícia. A argamassa confeccionada com o agregado " $\mathrm{D}$ " apresenta cristais de forma generalizada na matriz cimentícia, com formação de fissuras desencadeadas pela expansão dos mesmos, como demonstrado na Figura 9 (a). Como o agregado "D" não apresenta sulfetos em sua composição química, é provável que os cristais formados sejam originários da cristalização do gel higroscópico.

Na Figura 9 (b) pode-se notar a presença generalizada de gel na forma gretada e fissuras no poro da argamassa "D", enquanto na Figura 9 (c) é possível observar a presença de gel exsudado nos poros superficiais da barra de argamassa. A formação do gel está relacionada à maior presença de álcalis cálcio no agregado, presente em uma proporção maior que $7 \%$ na composição mineralógica do agregado. 

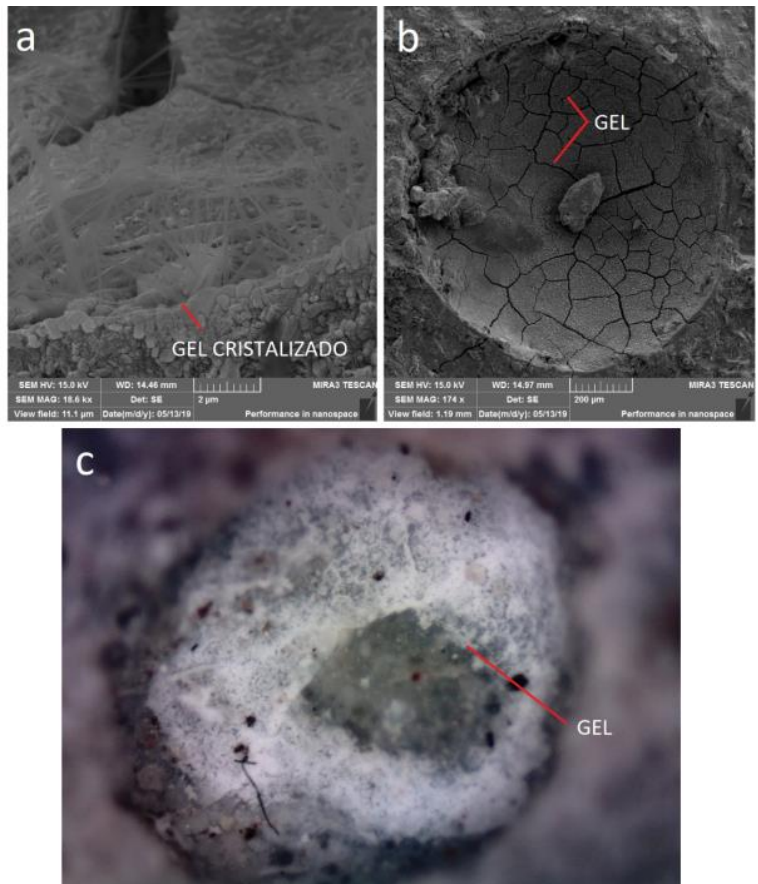

Figura 9: a) Presença de gel cristalizado com formação de fissuras. b) Presença generalizada de gel gretado em poro da argamassa com presença do agregado "D" e formação de fissuras. c) Exsudação do gel higroscópico em poro superficial.

Para o agregado "F" pode-se notar na microscopia a presença de cristais de etringita formados devido ao ataque interno por sulfatos, os quais estão presentes tanto na pasta de cimento endurecida quanto na própria superfície do agregado, como demonstrado na Figura 10 (a). Pode-se afirmar que esses cristais se originaram devido ao ataque interno por sulfatos, já que foram encontrados de forma generalizada na matriz cimentícia e pelo fato do agregado " $F$ " apresentar o sulfeto calcopirita em sua composição.
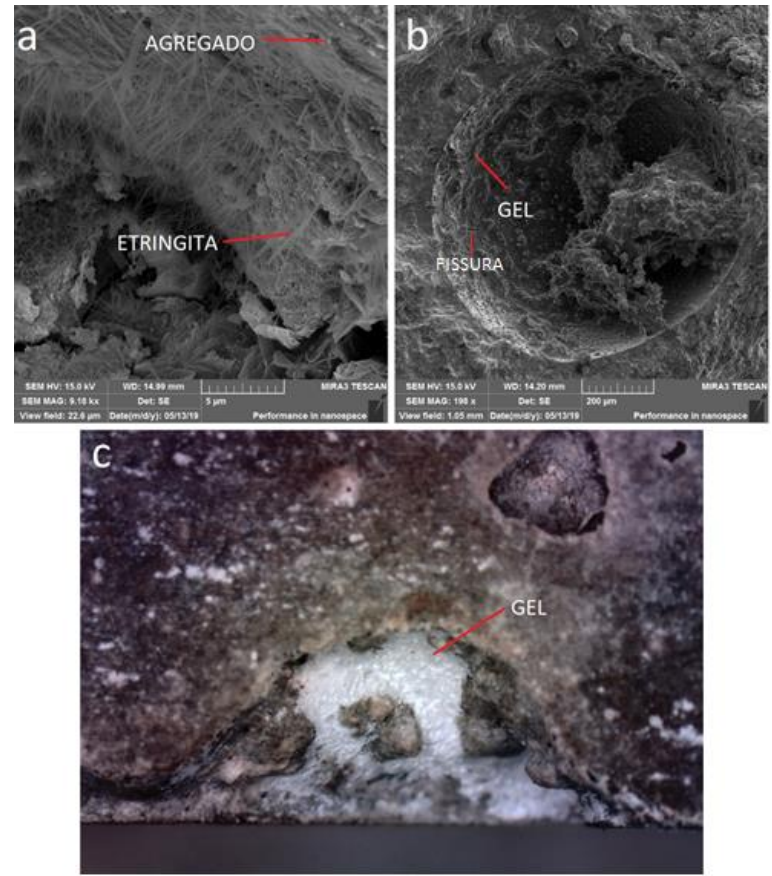

Figura 10: a) Presença generalizada de cristais de etringita formadas sobre o próprio agregado "F". b) Presença generalizada de gel em poro da argamassa com presença do agregado " $F$ ". c) Gel exsudado na região periférica da barra de argamassa. 
Observa-se na Figura 10 (b), a grande presença de gel devido à reação álcali-agregado no interior do poro da argamassa com agregado "F", assim como microfissuras geradas pela expansão do mesmo. Esse gel originou-se pelo fato de o agregado conter sílica não cristalizada e teores mais elevados de álcalis de cálcio, quando comparado com os demais agregados. Nota-se também na Figura 10 (c), a exsudação de gel para o exterior da barra de argamassa, por meio de microscópio óptico, reforçando o fato da ocorrência de gel higroscópico.

A difratometria da argamassa com o agregado da pedreira "F" apresentou fases de quartzo, calcita, portlandita e gipsita. Como o agregado "F" apresenta calcopirita em sua composição mineralógica, pode-se afirmar que a gipsita encontrada na argamassa é proveniente do ataque interno por sulfatos. Também nota-se a presença de halos amorfos próximos a picos de quartzo, mostrando que esse contém sílica amorfa e, assim como notado por meio de microscopia, propiciou a formação de gel higroscópico. O difratograma da argamassa contendo agregado da pedreira "F" é representado na Figura 11.

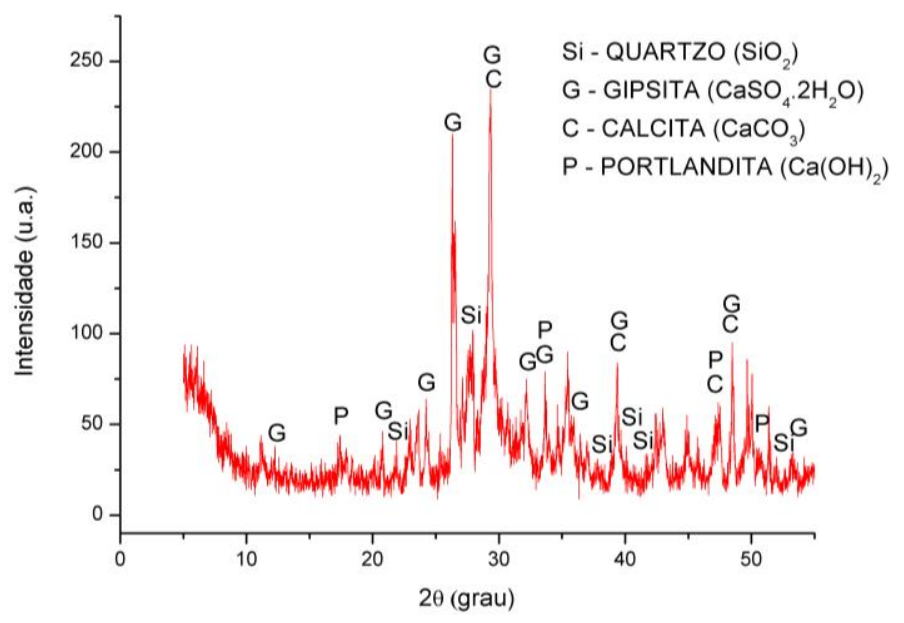

Figura 11: Difratograma de raio X da argamassa com agregado da pedreira "F".

A Tabela 2 mostra o resultado do ensaio de fluorescência de raios X realizado com as barras de argamassa após os 60 dias de cura. A porcentagem de óxidos de ferro encontrada para as barras confeccionadas com o agregado "F" é de $5,97 \%$, enquanto a média desse mesmo óxido nas demais barras foi de 3,28\%. Pode-se perceber que o óxido de ferro, presente em maior proporção na composição mineralógica do agregado " $F$ " (Tabela 1), aumenta também a proporção de óxidos de ferro na matriz cimentícia em geral. A maior presença de ferro na composição química desses agregados e, consequentemente na matriz cimentícia, juntamente com a presença de calcopirita no agregado, permitiu a catalisação das reações de formação de cristais provenientes do ISA, devido à maior difusão de íons ferro no interior dos poros da argamassa.

Tabela 2: Caracterização química da argamassa por fluorescências de raios $\mathrm{X}(\%)$.

\begin{tabular}{cccccccccc}
\hline Pedreira & $\mathbf{S i O}_{2}$ & $\mathbf{A l}_{2} \mathbf{O}_{3}$ & $\mathbf{K}_{2} \mathbf{O}$ & $\mathbf{C a O}$ & $\mathbf{N a}_{2} \mathbf{O}$ & $\mathbf{S O}_{3}$ & $\mathbf{F e}_{2} \mathbf{O}_{3}$ & $\mathbf{M g O}$ & $\mathbf{C O}_{2}$ \\
\hline $\mathbf{R E F}$ & 44,70 & 3,21 & 0,47 & 31,10 & 4,59 & 0,66 & 2,36 & 2,65 & 10,00 \\
\hline $\mathbf{A}$ & 35,90 & 6,89 & 1,52 & 30,70 & 5,56 & 0,60 & 2,40 & 2,32 & 13,50 \\
\hline $\mathbf{B}$ & 38,00 & 6,69 & 1,39 & 30,80 & 5,04 & 0,66 & 2,59 & 2,70 & 11,80 \\
\hline $\mathbf{C}$ & 37,80 & 7,03 & 1,83 & 33,10 & 5,31 & 0,64 & 2,46 & 2,69 & 8,83 \\
\hline $\mathbf{D}$ & 43,40 & 7,73 & 1,96 & 23,90 & 5,26 & 0,54 & 4,91 & 3,30 & 8,54 \\
\hline E & 46,30 & 8,77 & 4,45 & 22,10 & 5,14 & 0,61 & 2,29 & 1,71 & 8,44 \\
\hline F & 34,10 & 8,10 & 0,93 & 31,40 & 4,66 & 0,59 & 5,97 & 3,40 & 9,31 \\
\hline
\end{tabular}

Esse aumento no teor de ferro na matriz cimentícia também foi observado para o agregado " $D$ ", que apresenta o segundo maior teor de ferro na composição mineralógica (Tabela 1), entre os agregados estudados. Como pode-se notar na Tabela 2, a argamassa com agregado " $\mathrm{D}$ " apresenta um teor de óxido de ferro de 4,91\%, superior à média de 3,28\% das demais argamassas. Como esse agregado não apresenta sulfetos, acabou não apresentando a formação de cristais devido à ISA. Contudo, pode-se observar que quanto maior o teor de ferro no agregado, maior o teor de ferro na matriz cimentícia, revelando a ocorrência de difusão desses íons dos agregados para a matriz. 
Observou-se por meio de FRX (Tabela 2), que o aumento dos teores de cálcio e sódio nos agregados não levou à um consequente aumento nos teores desses compostos na matriz cimentícia. Esse processo ocorreu apenas com o ferro, como citado anteriormente. Porém, por meio de microscopia, notou-se que os agregados com as maiores porcentagens de álcalis cálcio e sódio, foram os que apresentaram formação de gel em contato com cimento (Tabela 1).

A maior presença de álcalis, na própria estrutura dos agregados, juntamente com a presença de sílica amorfa, permitiu um aumento na potencialização de formação do gel nos agregados "A", "B", “C”, "D" e "F". Diferentemente do ferro, os íons álcalis $\left(\mathrm{Ca}^{2+} \mathrm{e} \mathrm{Na}^{+}\right)$desses agregados não sofreram difusão nos poros da matriz cimentícia, permanecendo na própria estrutura do agregado e favorecendo a formação de gel.

\section{CONCLUSÕES}

As composições mineralógicas dos agregados das principais pedreiras utilizadas na região dos Campos Gerais, no Paraná, assim como a interação destes agregados em contato com o cimento, foram analisadas neste trabalho, permitindo assim uma caracterização das mesmas. Dos 7 (sete) agregados estudados, 5 (cinco) se apresentaram reativos à reação álcali-agregado ou ataque interno por sulfatos, de forma combinada ou isolada, ou seja, aproximadamente $70 \%$ das pedreiras analisadas.

Os agregados "A", "B", "C", "D" e "F" se mostraram reativos quanto à reação álcali-agregado. Esses agregados apresentaram porcentagens de sódio maiores que $5 \%$ ou de cálcio maiores que $7 \%$ nas suas composições, apresentando gel em diversos pontos da argamassa como visualizado na microscopia. Quanto ao ataque interno por sulfatos, os agregados da pedreira "F" se mostraram deletérios em contato com o cimento, ou seja, formaram cristais expansíveis no interior das barras de argamassa em decorrência do ataque interno por sulfatos. A formação dos cristais ocorreu devido à presença de calcopirita e de ferro na composição química do agregado.

Os agregados Referência e da pedreira "E” não apresentaram formação de gel nem de cristais em suas barras. Isso se deve à menores quantidades de sílica amorfa e aos menores teores de cálcio e sódio nesses agregados, e por não apresentarem sulfetos em sua composição química.

Vale ressaltar também que as argamassas confeccionadas com os agregados de maiores teores de ferro em sua composição mineralógica (agregados “ $\mathrm{D}$ " e " $\mathrm{F}$ ”), apresentaram também maior presença de ferro na matriz cimentícia, devido à difusão de íon ferro no interior das barras. Esse processo poderá ampliar a formação de cristais provenientes do ataque interno por sulfatos [15].

\section{AGRADECIMENTOS}

Agradecimentos a Universidade Estadual de Ponta Grossa pela infraestrutura oferecida ao desenvolvimento deste trabalho, em especial ao C-LABMU/UEPG e ao Laboratório de Construção Civil, assim como a Fundação Araucária e ao Conselho Nacional de Desenvolvimento Científico e Tecnológico (CNPq) pela concessão de bolsa auxílio e financiamento dos projetos.

\section{REFERÊNCIAS}

[1] VALDUGA, L.; PAULON, V. A. Reação Álcali-agregado: mapeamento de agregados reativos do estado de São Paulo. In: CONGRESSO BRASILEIRO DO CONCRETO, 46., 2004, Florianópolis. Anais do $46^{\circ}$ CBC, 2004. v. 1. p. 143-152.

[2] PEREIRA, E. Investigação de concretos afetados pela reação álcali-agregado e caracterização avançada do gel exsudado. 2015, 139 f. Tese (Doutorado em Engenharia e Ciência dos Materiais) - Universidade Federal do Paraná, Curitiba, 2015.

[3] HELENE, P. R. L,; MATOS, O.C. Avaliação experimental da corrosão de armaduras em concreto utilizando a técnica de medidas dos potenciais de eletrodo. São Paulo: EPUSP, 1992. 
[4] FORADADA, J. oS. Envejecimiento de presas por reacciones expansivas em hormigón. Minor thesis. Universitat Politècnica de Catalunya. Barcelona, 2005.

[5] FURNAS. Equipe de Laboratório de Concreto. Concreto massa, estrutural, projetado e compactado com rolo Ensaios e propriedades. São Paulo: Walton Pacelli de Andrade. PINI, 1997.

[6] MEHTA, P. K.; MONTEIRO, P. J. M. Concreto - estrutura, propriedades e materiais. São Paulo: Ed. Pini, 2008.

[7] HASPARYK, N. P. Investigação de concretos afetados pela reação álcali-agregado e caracterização avançada do gel exsudado. 2005, 326 f. Tese (Doutorado em Engenharia Civil) - Universidade Federal do Rio Grande do Sul. Porto Alegre, 2005.

[8] POOLE, A. B. Introduction to alkali-aggregate reaction in concrete. In: SWAMY, R. N. (Ed.). The alkali-silica reaction in concrete. Glasgow: Blackie and Son, p. 16-44, 1992.

[9] OLIVEIRA, I. Reacción sulfáticas interna en presas de hormigón: cinética del comportamiento. Tesis Doctoral. Universitat Politècnica de Catalunya. Departament d’Enginyeria de la Construcció. Barcelona, 2011.

[10] WERITZ, F.; TAFFE, A.; SCHAURICH, D.; WILSCH, G. Detailed depth profiles of sulfate ingress into concrete measured with laser induced breakdown spectroscopy. Constructon and Building Materials, v. 23, p. 275 - 283, 2009.

[11] ÇULLU, M.; ARSLAN, M. The effects of chemical attacks on physical and mechanical properties of concrete produced under cold weather conditions. Construction and Building Materials. vol. 57, pp. 53-60, 2014.

[12] NEVILLE, A. M. Propriedades do concreto. Tradução de Salvador Eugenio Giammusso. 2. ed. São Paulo: PINI, p. $827,1997$.

[13] HASPARYK, N. P. et al. Estudos de laboratório com concretos contendo agregados obtidos a partir de rocha com sulfetos. 15a. Reunión Técnica de la AATH - Seminario sobre Hormigones Especiales. Santa Fé - Argentina, 2003.

[14] AMERICAN SOCIETY FOR TESTING AND MATERIALS. ASTM C 1260: Standard Test Method for Potential Alkali Reactivity of Aggregates (Mortar-Bar Method). West Conshohocken, 2014.

[15] CASAnOVA, I.; AGUlló, L.; AGUADO, A. Aggregate expansivity due to sulfide oxidation - I. Reactions system and rate model. Cement and Concrete Research. v. 26, nº 7, p. 993-998, 1996. 